\section{Bones and groans}

As a general practitioner to whom patients presumably look for a source of disinterested information about their health, I have difficulty knowing what to make of the latest recommendations in the osteoporosis clinical practice guidelines $^{1}$ and accompanying commentary. ${ }^{2}$ Contained therein is an expanded list of indications for testing and drug treatment for osteoporosis as recommended by a group of 13 Canadian academics, bolstered by an endorsement from an international expert.

The now standard list of competing interests in those articles reveals that of the 13 academics, 10 list a total of 131 pharmaceutical corporate sponsors (an average of 13 each). The author of the supporting commentary lists 47 national divisions of 32 pharmaceutical corporate sponsors, in addition to the European Federation of Pharmaceutical Industries and Associations.

If nothing else, this revelation suggests that, as bone density goes down, medical profits go up. But are patients receiving good value for their investment? We continue to look forward to an independent cost-benefit analysis as our publicly funded health system groans under the collective weight of screening orthodoxy. Perhaps the three independent academics on the panel could be invited to write a minority opinion.
Presumably it is only a matter of time until governments add osteoporosis screening to the list of conditions for which general practitioners are paid search-and-destroy screening incentive bonuses - at which point we will all stop asking questions and instead be content that the public is being well served through the continuing wholesale adoption of pharmaceutical industry guidelines.

\section{Alban C. Goddard Hill BSc MD Belleville, Ont.}

\section{References}

1. Papaioannou A, Morin S, Cheung AM, et al. 2010 clinical practice guidelines for the diagnosis and management of osteoporosis in Canada: summary. CMAJ 2010;182:1864-73.

2. Kanis JA. New osteoporosis guidelines for Canada. CMAJ 2010;182:1829-30.

CMAJ 2011. DOI:10.1503/cmaj.111-2009

\section{Canada's e-health software mess: simple solution}

The manner in which electronic medical record (EMR) applications are being introduced in Canada is totally reminiscent of the drug industry: push for sales at all costs and without regard for unintended consequences and cost. ${ }^{1}$ Unfortunately, we are hoodwinked into believing that the applications subsidized by government are superior. If we want the best product, government should pay us

\title{
CORRECTION
}

\section{Exercise training may improve post-thrombotic syndrome}

In the Jan. 11 issue of $C M A J,{ }^{1}$ a portion of Dr. Susan Kahn's competing interests statement was written incorrectly. The statement should have read, with the correction in italics: [Kahn] is a coapplicant and steering committee member on an NIH-funded trial ... of pharmacomechanical catheter-directed thrombolysis plus standard anticoagulation versus standard anticoagulation alone to prevent post-thrombotic syndrome after deep venous thrombosis." CMAJ apologizes for any inconvenience this error may have caused.

\section{Reference}

1. Kahn SR, Shrier I, Shaprio S, et al. Six-month exercise training program to treat post-thrombotic syndrome: a randomized controlled two-centre trial. CMAJ 2011;183:37-44.

CMAJ 2011. DOI:10.1503/cmaj.111-2007

for using an EMR - a premium of $20 \%$ might begin to make up for the extra time it takes to write prescriptions, fill out requisitions and deal with laboratory data and investigations. Physicians would quickly find the best product, and vendors would have to compete on quality and cost-effectiveness to survive.

A word of advice to physicians who are considering buying an EMR application: ask vendors to provide you with the full use of their product free of charge for three months. Have nothing to do with those unwilling to comply. I am a current user who is very disappointed with the primitive state of EMR applications available in Canada, especially compared with those in Portugal, the Netherlands, Denmark and other countries.

Gerald J.M. Tevaarwerk MD

Victoria, BC

\section{Reference}

1. Webster PC. Canada's ehealth software “Tower of Babel." CMAJ 2010;182:1945-6.

CMAJ 2011. DOI:10.1503/cmaj.111-2008

\section{Public engagement in choosing health priorities}

We at the Canadian Agency for Drugs and Technologies in Health (CADTH) could not agree more with the points made in this issue of the journal by Chafe, Levinson and Hébert about the merits of public engagement. ${ }^{1}$ That is why the agency has had two public representatives as members on its 13-person Canadian Expert Drug Advisory Committee (CEDAC) since October 2006.

With the rising cost of many new drugs, it is increasingly important that the public viewpoint is represented when CEDAC considers issues relating to equitable access to medications. The appointment of two public members to the committee was a substantial step in CADTH's public involvement initiative. These members, selected from a diverse group of applicants, are expected to represent the broader public interest. They have the same voting rights as CEDAC members, with all the 